\title{
THERMOSPHERIC HEATING AT HIGH LATITUDES AS OBSERVED FROM INTERCOSMOS-BULGARIA-1300 AND DYNAMICS EXPLORER-B
}

\author{
Ts. P. Dachev, ${ }^{*}$ K. B. Serafimov, ${ }^{*}$ A. Bochev, ${ }^{*}$ \\ I. S. Kutiev, ${ }^{*}$ I. G. Rumchev, ${ }^{*}$ Yu. N. Matviichuk* \\ and G. R. Carignan** \\ *Central Laboratory for Space Research, Bulgarian Academy of \\ Sciences, 6 Moskovska str., Sofia 1000, Bulgaria \\ **Space Physics Research Laboratory, University of Michigan, \\ Ann Arbor, MI 48109, U.S.A.
}

ABSTRACT

This paper reports the results of the first direct comparison of near simultaneous measurements obtained by the INTERCOSMOS-BULGARIA-I300 and the DYNAMICS EXPLORER-B satellites. The ICB-1300 is in a near circular orbit at a mean height of about $850 \mathrm{~km}$. The DE-B satellite in an elljptical orbit is sometimes directly below the ICB-1300 satellite providing an opportunity to investigate the response of the thermosphere to particle fluxes from the magnetosphere. Energy fluxes in the rance $0.2-15 \mathrm{keV}$ are obtained from an energetic particle analyzer on board the ICB-1300 satellite. The thermospheric composition and density are obtained by a neutral gas mass spectrometer (NACS) on the DE-B satellite. During the period 20 August - 20 November, 1981, observations show that the times and locations of maxima in magnetospheric energy deposition coincide with regions of maximum thermospheric upwelling characterized by composition changes.

\section{INTRODUCTION}

The density and temperature distributions of the neutral atmospheric constituents in the thermosphere are directly connected to the processes of mass, energy and momentum transport from the middle atmosphere beneath, and to ionosphere magnetospheric processes $/ 1 /$. The thermosphere dynamics at high latitudes are determined mainly by atmospheric pressure gradients, by the energy deposited by particle fluxes, and by ionospheric current dissipation 12\%. Locally, in the thermosphere, the energy input is manifested by relative minima of the constituents with mass numbers less than the mean mass, and maxima of the constituents with masses greater than the mean mass $13,4 \%$ Joule heating and heating by particle precipitation are the two most important energy sources of maqnetospheric origin. The heating by solar ultraviolet radiation is important at low and middle latitudes and excedes substantially the heating by particles and currents, but at auroral latitudes the heating by fields and particles is comparable and may even excede the heating by solar ultraviolet $/ 5 /$.

The "Intercosmos - Bulgaria - 1300" (TCB - 1300) and "Dynamic Explorer - B" (DE - B) satellites can be used together for the determination of the distribution of the high-latitude heating in the thermosphere. The "Intercosmos - Bulgaria - 1300" satellite /6/ has a nearly circular orbit with a perigee of $825 \mathrm{~km}$ and an apogee of $905 \mathrm{~km}$. It can measure the particle fluxes /7/ as well as the field-aligned magnetospheric currents /8/ near the upper boundary of the thermosphere. The "Dynamics Explorer - B" sateliite $/ 9 /$ is in an eccentric orbit with a perigee of $300 \mathrm{~km}$ and apogee of $1000 \mathrm{~km}$. Instruments onboard the satellite $110,11,12 /$ for measuring the neutral density, temperature and winds provide data for thermospheric conditions.

\section{ME ASUREMENT TECHNIOUE}

The neutral density and composition used in this work were obtained by a quadrupole mass spectrometer (NACS) on the DE-B satellite /10/. The ion and electron flux measurements in the energy range 0.2 - $15 \mathrm{kev}$ were obtained from the low-energy particle analyzer (ANEPE) on the ICB - 1300 satellite, Data for the electron and ion flux with pitch-angle near $0^{\circ}$ in the auroral zone are used. The measured spectra are processed by the technique described in $/ 14 /$, and the total energy deposition is calculated.

EXPERIMENTAL DATA

The "Intercosmos - Bulgaria - 1300" and "Dynamics Explorer" data for the period August November 1981 are analyzed for local evidence of topside atmosphere heating, and for the global behavior of the energy carried by particle fluxes and also for the peculiarities of 
the distribution of neutral atmospheric constituents. In Figure la. the "ICB - 1300" and "DE - B" orbits are presented for 19 September 1981 (day 81262) in the interval 5 - 8 UT. It is seen that the trajectories do not differ much, and in the region of comparison their longitudinal displacement is $0^{\circ}$ to $40^{\circ}$. The UT displacement of the two orbits is about 3 hours. In the northern hemisphere (40,90, ILAT) the "DE - B" satellite universal time is $8: 59$ - 9:10, and the UT of "ICB - 1300" satellite is 5:59 - 6:12.

The "ICB - 1300" is at ^ $850 \mathrm{~km}$ height, and the "DE - B" altitude is $465 \mathrm{~km}$ at the pole and increasing equatorward. The local times for two satellites is 18 - 21 LT for "ICB - 1300 and $2300 \mathrm{LT}$ for "DE - B". In the last 6 hours of UT on 18 september a moderate geomagnetic storm is observed with a maximum value of the Kp index equal to 6- (21.00 - 24.00 UT). On September $19 \mathrm{kp}$. reaches its maximum value of 6 in the interval 6 - 9 Ur, and Ap reaches the value of 38. During the measurement periods the $\mathrm{Kp}$ values are $4+$ for $\mathrm{DE}-\mathrm{B}$ and 6 for "ICB1300". The chosen UT displacement of 3 hours is sultable for the data comparison because it eliminates a local time displacement of 3 hours, and allows the neutral atmosphere disturbances to be measured following a precipitation event /15/. The satellites path in the high latitude region is also seen in Figure lb. in MLT/ILAT coordinates. Because the DE - B satellite is in an orbit with 90 inclination it reaches 82.2 ILAT, while ICB - 1300 reaches 74.5 .



Fig. la. The projections of the ICB - 1300 (dotted line) and $\mathrm{DE}-\mathrm{B}$ (asterix line) orbits in the northern hemisphere.

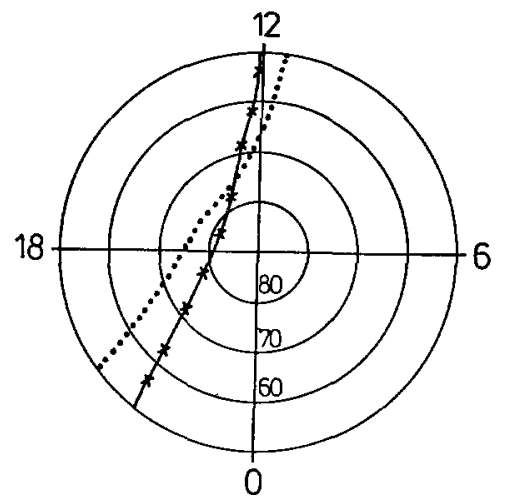

Fig. lb. The same as Fig. la. (MLI, ILAT) reference system.

In Figure 2 the data from the two satellites are shown for the crossing of the afternoon sector. The x-coordinate is invariant latitude - ILAT. The upper pannel (Figure 2a) presents the $1 \mathrm{keV}$ particle flux variations, and the energy flux carried by $0.2-15 \mathrm{keV}$ electrons. A continuous increase of the energy and particle fluxes is seen with a maximum in the region of the oval with coordinates ILAT $=65.5$ and MLT= 19:00. In Figure 2b the NACS data reduced to $300 \mathrm{~km}$ altitude $/ 4 /$, are presented. The altitude in the region of the minimum helium concentration is $526 \mathrm{~km}$, so only the oxygen and the helium data are presented (the instrument sensitivity does not allow for the reliable measurement of the remaining atmospheric constituents at such a height). The helium concentration is multiplied by a factor of 100 so that it can be presented on the same scale with the oxygen concentration. It is seen in Figure $2 \mathrm{a}$ and $2 \mathrm{~b}$ that the particle and energy flux maxima essentially coincide with the minimum in the helium concentrations, indicating a region with maximum neutral temperature and, therefore, maximum convection.

In Figure 3 the following parameters measured on DF - B (orbit 1217) are shown: neutral temperature, the vertical component of the neutral wind and densities of the neutral constituents - atomic oxygen (denoted as 0), molecular nitrogen (N), helium (He) and argon (Ar). The neutral constituent densities are reduced to the standard altitude by the technique described in /4/. The neutral temperature ( $\mathrm{Tn}$ ) and the vertical wind (Vn) are measured by the instrument WATS $/ 12,15 /$, and the neutral density by NACS. perigee is situated in the dusk sector at $88^{\circ}$ geographic latitude (marked by an arrow and the letter P). The data in orbit 1217 are measured on 24 October 1981. (day 81297) between 21:00 and 21:17 UT. During the time of the measurements $\mathrm{Kp}$ has the value of $3+$. Ap is 18 for the day, Locations and times are indicated along the abscissa.

In Figure 3, three consecutive maxima in argon density are observed. None of these coincide with the satellite perigee, indicating their dynamical origin. The maxima 1 and 2 coincide with the daw and dusk ovals and their coordinates in (MLT, ILAT) are $\left(18: 42,66.2^{\circ}\right.$ ) and (10:36, 74.4\%) respectively. The central maximum coincides with the south polar cap. The argon density maximum in the dusk sector coincides with extreme values of all other thermospheric parameters presented in the figure: the helium and oxygen have a local minimum, and $\mathrm{N}$ has a maximum. The neutral temperature measured from $\mathrm{N}_{2}$, rearhes a value of about $1600^{\circ 2} \mathrm{~K}$, and the upward vertical wind velocity is about $70 \mathrm{~m} / \mathrm{s}^{2}$. In the oval region a 
maximum in the energy deposition by particle fluxes and fields at the altitudes of 100 - 200 $\mathrm{km}$ is expected. The energy dissipation maximum is accompanied by a local temperature maximum. An upward convective motion appears, upwelling the thermosphere in the whole altitude range.

From Figure 2 and 3 it can be concluded that, in the distribution of the thermospheric constituents, an important role is played by the energy fluxes of magnetospheric - ionospheric origin which are under a strong magnetic control. This magnetic control is exhibited by the global thermospheric parameter distribution.

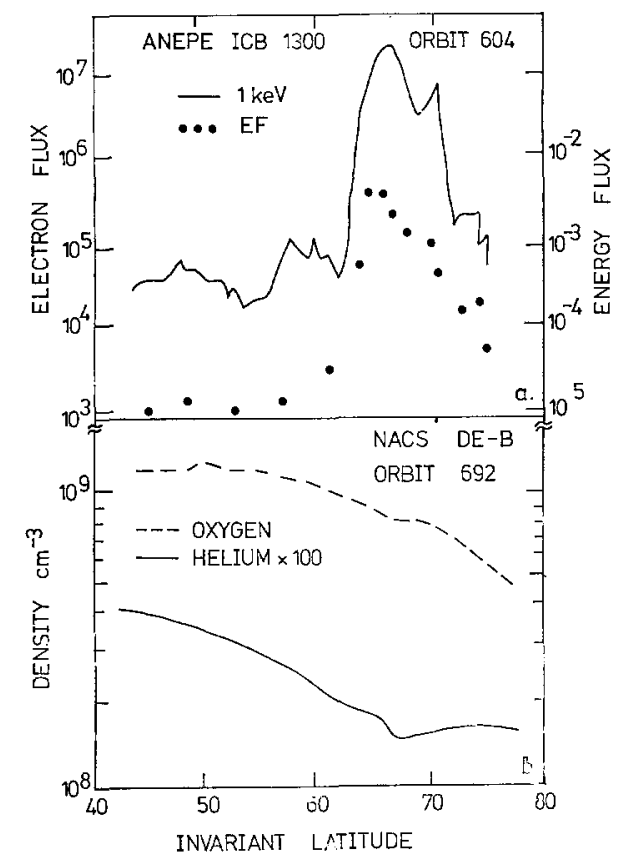

Fig. 2a. The distribution of the energy flux carried by 0.2 - $1.5 \mathrm{keV}$ electrons and the $1 \mathrm{kev}$ particles energy flux by data from the "ICB - 1300" satellite orbit 605 .

Fig. 2b. Neutral oxygen and helium density distribution by data from the NACS instrument aboard the DE - B satellite orbit 692 .

In Figure 4 the global distribution of atomic oxygen reduced to an altitude of $300 \mathrm{Km}$ is shown for the southern hemisphere. The data are taken between 15 and 18 october (day 81288 to 81291) from $41 \mathrm{DE}$ - B orbits. For this interval the satellite perigee varies in geographic latitude between $52^{\circ}$ and $67^{\circ}$. Only the morning parts of the satellite orbits are used and the local time is the same for the whole hemisphere - about 9:00 IT. The magnetic conditions in this period are not disturbed - Ap $\leq 20$, the maximum $\mathrm{Kp}$ is $4+$. It is seen that the oxygen isolines are very similar to the invariant latitude distribution. A deep 8 minimum of the density is formed in the region of the south polar cap with values of $2 \times 10^{8}$ $\mathrm{cm}^{-3}$. In the region $(-100,-30)$ LONG and $(-10,-35)$ LAII a maximum in the oxygen concentration is seen with values of $9 \times 10^{8} \mathrm{~cm}^{-3}$. For heliurn the density isolines distribution is similar to that for the oxygen $/ 4,18 \%$, and the constituents with masses higher than the mean mass show distributions with reversed maxima and minima, i.e. in the regions of the oval and the polar cap local density maxima are observed /4/.

In Figure 5 the distribution of the 0.2 - $15 \mathrm{keV}$ electron energy flux is shown by data of the "ICB - 1300" satellite. The energy is calculated in erg/cm/sec/ster. The data of 35 "ICB - 1300" transits over the southern hemisphere are used for the calculation of the energy flux. The data are taken in the period 20 August 1981 - 20 November 1981 in the same local time interval as the $\mathrm{DE}-\mathrm{B}$ data, and are only from the days with Ap<20. Because the variations in the energy flux are very high, the data have been smoothed by averaging into $10^{\circ}$ longitudinal and $5^{\circ}$ latitudinal intervals. The data are in the local time interval 3:00 $-11: 00 \mathrm{IT}$. 


\section{DYNAMICS EXPLORER-B}

\section{NACS 81288-81291 OXYGEN LT=9: QD ALT=3ØØ}

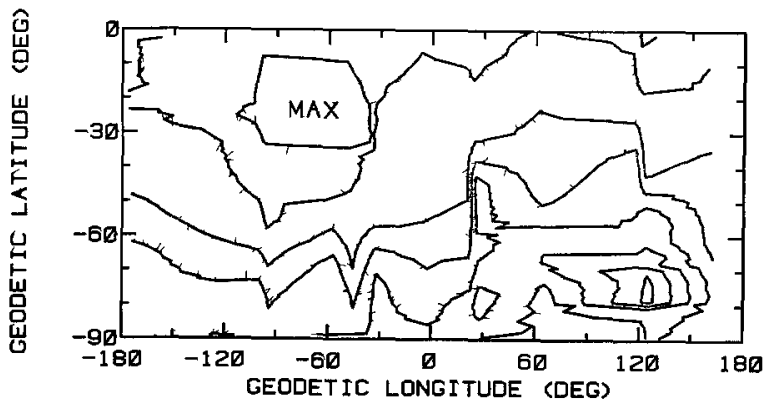

Fig. 4. Distribution of the neutral oxygen corcentration in the southern hemisphere by data from the NACS.

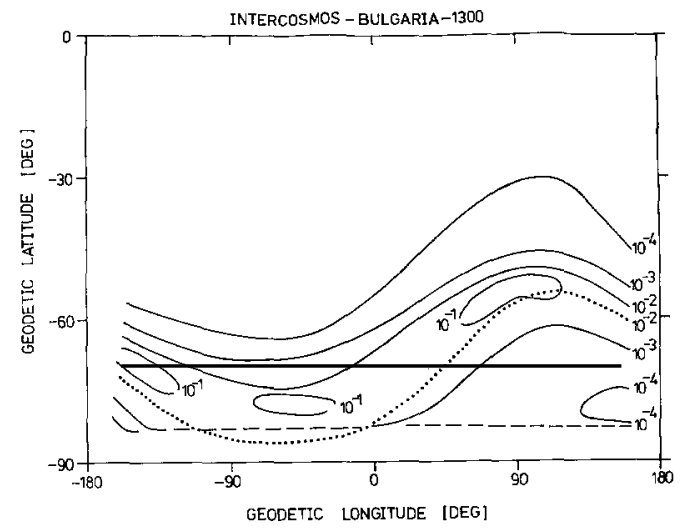

Fig. 5. Distribution of the $0.2-15 \mathrm{keV}$ electrons energy flux in erg/cm/sec/ster in the southern hemisphere by data from the "ICB - 1300" satellite.

It is seen from Figure 5 that the energy flux is distributed symmetrically about invariant latitude $70^{\circ}$ (marked in the figure by a dotted line). The effect of the narrowing of the zone with more energetic electrons toward the oval center is well known /19/. This effect is apparent also in the ANEPE data /20/ and leads to an increased energy flux, because of the higher electron energies. The energy fluxes, carried by ions, are also investigated. Their distribution is similar to the one shown in Figure 5, but with a maximum shifted by 8 - 10 ILAT towards the equator /21/. The ion-carried energy is one order of magnitude lower than the energy shown in Figure 5.

\section{CONCLUSION}

The observed local and global features of the distribution of the thermospheric parameters from the DE - B satellite in the oval region are well correlated with the energy flux distribution observed by the "ICB - 1300" satellite. Many questions still remain regarding the local thermospheric heating particularly in the polar cap region.

\section{ACKNOWLEDGEMENTS}

The authors thank N.W. Spencer and L.E. Wharton for the data from the WATS instrument aboard the DE - B satellite, and also K. Georgieva and M. Sukigian for their help in the preparation of this paper.

\section{REFERENCES}

I. R.G. Roble, Rex. Geophys. Space Phys. 21, 217, (1983)

2. B.H. Ahn, S.I. Akasofu, and Y. Kamide, J. Geophys. Res. 88, 6275, (1983).

3. H. Volland, J. Atmos. Terr. Phys. 41, 853, (1979). 
4. G.R. Carignan, T. Dachev, A.E. Hedin, C.A. Reber, and N.W. Spencer Geophys. Res. Lett. 9, 949, (1982).

5. J.F. Vickrey, R.R. Vondrak, and S.J. Matthevs, J. Geophys. Res. 87, 5184, (1982).

6. K. Serafimov, I. Kutiev, S. Chapkunov, M. Gogoshev, V. Adasko, V. Balebanov, A. Bochev, T. Dachev, I. Ivanow, A. Josifjan, I. Podgorny, and Sheremetjevsky, Space: Mankind $\mathrm{S}$ foert Environment, Ohford, Pergamon Press, 1982.

7. K. Serafimov, S. Chapkunov, M. Gogoshev, I. Kutiev, M. Gogosheva, T. Ivanova, N. Petkov, T. Samardjiev, and S. Sargoichev, Acta Astronautica, 10, 263, (1983).

8. G. Stanev, M. Petrunova, W. Teodosiev, I. Kutiev, K. Serafinov, S. Chapkunov, V. Chmyrev, N. Isaev, Puschaev, I. Timenov, and S. Bilichanko, Adv. Space Res. 2, N7, 43, (1983).

9. R.A. Hoffman, G.D. Hogan, and R.C. Machl, Space Sci. Inst. 5, 349, (1981).

10. G.R. Carignan, B.P. Block, J.C. Maurer, A.E. Hedin, C.A. Reber, and N.W. Spencer, Space Sci. Inst. 5, 429, (1981).

11. P.B. Hays, T.L. Killeen, and B.C. Kennedy, Space Sci. Instr. 5, 395, (1981).

12. N.W. Spencer, L.E. Wharton, H.B. Niemann, A.E. Hedin, G.R. Carignan, and J.C. Maurer, Space Sci. Instr. 5,417 , (1981).

13. In Ivanov, P. Nenovski, T. Dachev, J. Semkova, R. Koleva, S. Chapkunov, I. Kutiev, K. Kanev, and A. Kanchev, 32 IA Congress Roma, paper N IAF - 8I - 218, Italy, (198I).

14. I. Kutiev, A. Bochev, M. Gogoshev, M. Gergikova, Y. Matviichuk, L. Bankov, and N. Bankov, Adv. Space Res. 2, \# 10, 97, (1983).

15. N.W. Spencer, L.E. Wharton, G.R. Carignan, and J.C. Maurer, Geophys. Res. Lett. 9, 953, (1982).

16. P.H. Smìth, C.H. Freeman, and R.A. Hoffman, Space Sci. Instr. 5, 561, (1981).

17. P.B. Hays, R.A. Jones, and M.H. Rees, Planet. Space Sci. 21, 559, (1973).

18. T.P. Dachev, G.R. Carignan, and P.G. Marinov, paper X.4.6., XXV COSPAR, Graz, Austria, (1984).

19. F. Gambon, and Y.I. Galperin, Ainn. Geophys. 38, 87, (1982).

20. K. Serafimov, I. Kutiev, A. Bochev, T. Dachev, I, Bankov, N. Bankov, P. Marinov, N. Balebanov, V. Dubinin, E. Nikolaeva, P. Izrkelevich, P. Halipov, G. Gdalevich, paper 9.3.8., XXV COSPAR, Graz, Austria, (1984).

21. H.D. Voss and L.G. Smith, I. Atmos. Perr. Phys. 42, 2.27, (1980). 